\title{
Key vacuum technology issues to be solved in evacuated tube transportation
}

\author{
Yaoping ZHANG ${ }^{1 *}$, Daryl OSTER ${ }^{2}$, Masayuki KUMADA ${ }^{3}$, Jianye YU ${ }^{1}$, Shengshan $\mathrm{LI}^{1}$ \\ 1. Institute of Evacuated Tube Transportation, Xijing University, Xi' an 710123, China \\ 2. ET3.COM INC., Crystal River Florida 34423-1423, USA \\ 3. Feynman Co. Ltd., 4-5-11 Azuma Tsukuba 305-0031, Japan
}

\begin{abstract}
Evacuated tube transportation (ETT) will be one of the ultra-large-scale vacuum application areas. This paper lists some key vacuum technology issues in ETT: (1) how to construct ultra-large-scale vacuum chamber with lower cost and high reliability, (2) how to evacuate gas out of the ETT tube in short time, (3) how to release heat or reduce temperature in the vacuum tube, (4) how to avoid vacuum discharge, (5) how to make vehicles with airproof shells and life support system, and (6) how to detect leaks and find leak positions efficiently. At the same time, some solutions are proposed.
\end{abstract}

Key words: vacuum technology; evacuated tube transportation; vacuum tube; Maglev

(C) 2011 JMT. All rights reserved.

\section{Introduction}

C ompared with the developed Internet or IT technology, the current situation of transportation appears to be sluggish. People are looking forward to a transport mode that will be faster, cleaner, and environmentally friendly. The speed of high-speed railway is $350 \mathrm{~km} / \mathrm{h}$ [1], the speed of the Shanghai Maglev in operation in China is $430 \mathrm{~km} / \mathrm{h}$ [2], and that of Yamanashi Maglev in Japan has reached $581 \mathrm{~km} / \mathrm{h}$ [3]. However, they are not the ideal speeds compared to evacuated tube transportation (ETT), and those trains create high aerodynamic noise and resistance. It will be the right orientation for trains to combine with evacuated tube transportation, namely putting the Maglev into the vacuum tube of ETT. Then the Maglev could run at a speed of $600-1000 \mathrm{~km} / \mathrm{h}$, and it is possible to run at a hypersonic speed, for example, $6000 \mathrm{~km} / \mathrm{h}$ or even over $10000 \mathrm{~km} / \mathrm{h}[4]$.

To the authors' knowledge, however, only a few studies [5-6] have been conducted on the ETT. In order to operate a Maglev in a vacuum tube, a series of vacuum technology problems need to be studied and solved.

Received Jan. 19, 2011; revision accepted Mar. 8, 2011

*Corresponding author. Tel.: +86-29-85628124

Email: tubetrans@hotmail.com (Y.P. ZHANG) doi: 10.3969/j.issn.2095-087X.2011.02.006
This paper lists and discusses some key vacuum technology issues to be solved in ETT.

\section{Constructing ultra-large-scale vacuum chamber}

The ETT vacuum chamber will be a circular tube with an inside diameter of about $2-5 \mathrm{~m}$ and a length of $1000-15000 \mathrm{~km}$. For such a large vacuum chamber, construction costs must be considered seriously. We should select feasible construction materials and design structures. One should consider at first how to construct an ultra-large-scale vacuum chamber with lower cost and high reliability. Common steel and cement are cheap building materials and they are also appropriate for making a vacuum tube. With steel and cement, three types of vacuum tube structure are suggested in this paper.

\subsection{Pure steel tube}

The advantage of pure steel tube is that it is easy to guarantee airproof, and its cost is moderate. The current price of steel in China market is about $5000 \mathrm{CNY}$ per ton. To estimate vacuum tube cost, we presume that the wall thickness of tubes are $20 \mathrm{~mm}, 18 \mathrm{~mm}, 16 \mathrm{~mm}$, and $14 \mathrm{~mm}$, for tubes with inside diameter of $5 \mathrm{~m}, 4 \mathrm{~m}, 3 \mathrm{~m}$, and $2 \mathrm{~m}$, respectively, as shown in Fig. 1. Then the basic materials cost of steel tube per kilometer are as shown in Table 1. 

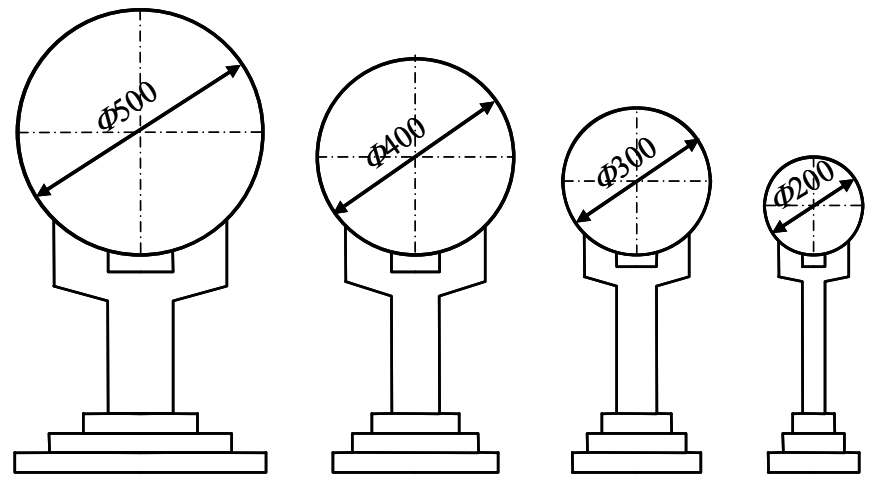

Fig. 1 Sketch of vacuum tubes with different inside diameters (unit: $\mathrm{cm}$ )

Table 1 Basic materials cost of steel tube per kilometer

\begin{tabular}{ccccc}
\hline Tube diameter $(\mathrm{m})$ & $\begin{array}{c}\text { Wall thickness } \\
(\mathrm{mm})\end{array}$ & $\begin{array}{c}\text { Materials volume } \\
\left(\mathrm{m}^{3}\right)\end{array}$ & $\begin{array}{c}\text { Materials weight } \\
(\mathrm{t})\end{array}$ & $\begin{array}{c}\text { Cost per } \\
\text { kilometer }(\mathrm{CNY})\end{array}$ \\
\hline 5 & 20 & 315.2560 & 2459.0 & 12295000 \\
4 & 18 & 227.0974 & 1771.4 & 8856800 \\
3 & 16 & 151.5238 & 1181.9 & 5909400 \\
2 & 14 & 88.5354 & 690.6 & 3452900 \\
\hline
\end{tabular}

\subsection{Composite structure tube with steel and concrete}

In order to further reduce materials cost and increase the intensity of a vacuum tube, a composite structure tube is acceptable.

As shown in Fig. 2, a composite structure tube consists of an inner steel tube with a thin wall and outer concrete layer.

In this case, the inner steel tube wall thickness would be less than $10 \mathrm{~mm}$, even $3 \mathrm{~mm}$. Although the total thickness of the tube wall may be increased, the total

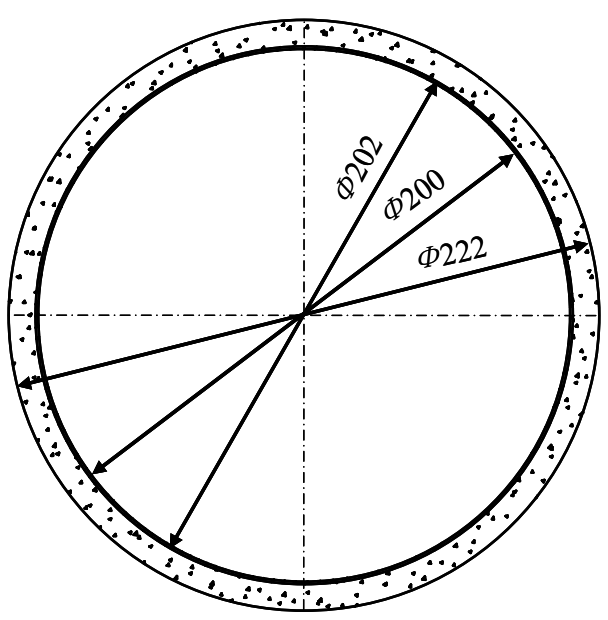

Fig. 2 Composite structure tube with inner thin wall steel tube and outer concrete layer (unit: $\mathrm{cm}$ ) materials cost can be reduced because the price of concrete is much less than the price of steel. In addition, the compressive strength would be increased, which is significant for the vacuum tube.

The steel airproof layer could also be considered outside the concrete tube [7]. In this case, the advantage is that the steel layer would not likely be stuck on the concrete tube when it is compressed by the atmospheric pressure. The disadvantage is that the steel layer is apt to damage or erosion.

\subsection{Concrete tube with steel ribs}

If some types of thin film or airproof materials with low price are attainable, concrete tubes with steel ribs would be feasible.

\section{Evacuating gas out of the ETT tube}

How to efficiently evacuate gas out of the ETT tube in short time is another key issue for ETT systems. For an ultra-large-scale vacuum chamber, the allowable time to evacuate gas from it will be quite short, for example, to evacuate gas from trunk tube within $1-2 \mathrm{~h}$ and evacuate gas from the airlock in a few minutes. Therefore, it is necessary to install vacuum pumps every 1 or $2 \mathrm{~km}$, and the pumping speed of vacuum pumps or pump groups should be large enough. 
Along the ETT line, airproof isolation gates should be set every $5-10 \mathrm{~km}$ as shown in Fig. 3. One of functions of the isolation gates is to evacuate gas from the tube efficiently. After all isolation gates are closed, gas is evacuated from each section of vacuum tubes. When the atmospheric pressure in each section reaches the specified value, all vacuum pumps stop working and all isolation gates are opened. Then the Maglev can run through. Another function of the isolation gate is for facilitating checking airproof and leakage of each section of the ETT tube, because it is difficult for whole tube to check airproof and leakage.

Among current vacuum pumps, Roots pumps are right for evacuating gas from ETT tubes. Roots pump has high pumping speed, simple structure and low price. The maximum pumping speed of Roots vacuum pumps is more than $12000 \mathrm{~L} / \mathrm{s}$.

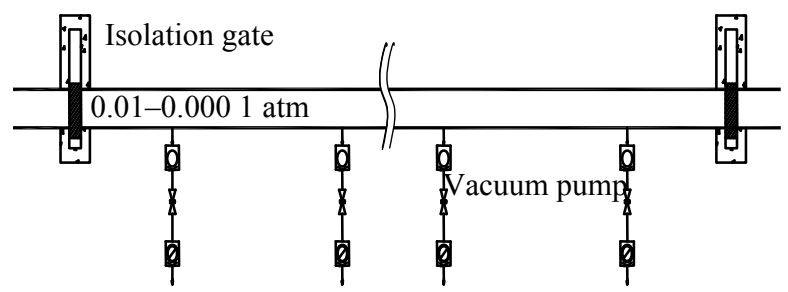

Fig. 3 Setting of gas isolation gates and pumps along vacuum tube

\section{Releasing heat or reducing temperature in the vacuum tube}

In ETT tube, there are some heat resources leading to a temperature rise:

(1) Electrical devices operation such as linear motor drives the Maglev.

(2) Aerodynamics heating when the Maglev runs at a high speed in the vacuum tube. There is also a little gas in the tube because it will be rough vacuum inside it.

(3) The Maglev vehicles releasing heat.

(4) Solar radiant heat through the tube wall when the ETT tube is put on the ground.

Because there is no air convection in ETT tube and the vacuum circumstance acts as a heat isolation medium, heat in ETT tube would accumulate, and temperature would rise continuously. Thus, we should find methods to release heat.

(1) We should select tube wall structures and materials that facilitate the release of heat. In this sense, a steel tube is better than a concrete tube, and common steel is better than stainless steel because the thermal conductivity of stainless steel is much less than that of common steel. At the same time, the tube wall thickness should be as thin as possible.
(2) The ETT tube should be put as far under ground as possible because there is a constant temperature environment under ground and no solar radiation.

(3) A metal pipe with recycled cold water is effective for reducing temperature in the ETT tube. The detailed methods are discussed in [8].

(4) An ETT system with the driving system outside the tube is effective for reducing heat in the tube. The detailed scheme is shown in [9].

\section{Avoiding vacuum discharge}

Electricity is apt to break in a vacuum environment more easily. Vacuum discharge characteristics are not generally considered for some electrical components of the Maglev in open space, but it must be considered in a vacuum tube. In order to avoid vacuum discharge in the ETT tube, some suggestions are given as follows:

(1) Prohibit installing uninsulated wire in ETT tube.

(2) Do not keep wire of a linear motor in uninsulated. For some wires or electrodes that have to be uninsulated in the linear motor, a safe space from other uninsulated wires or electrodes should be maintained.

(3) Do not use uninsulated wires on the Maglev. For some wires or electrodes that have to be uninsulated in the Maglev of vacuum tube, a safe space from other uninsulated wires or electrodes should be maintained.

\section{Making vehicles with airproof shells and life support systems}

ETT vehicles will run in a vacuum environment, $1 \mathrm{~atm}$ in the vehicle and $0.01-0.0001 \mathrm{~atm}(1013-$ $10.13 \mathrm{~Pa}$ ) outside the vehicle, as shown in Fig. 4. There-



Fig. 4 Sketch of the vehicle with inner pressure $1 \mathrm{~atm}$ and the vacuum tube with inner pressure 0.01-0.000 1 atm 
fore the vehicle should be designed according to following three principles:

(1) ETT vehicle shells must be airproof and strong enough to endure the pressure inside the vehicles.

(2) Oxygen must be provided and an air conditioner must be installed inside passenger vehicles.

(3) A life support system in the passenger ETT vehicle is needed.

It is necessary to make vehicles with airproof shells and a life support system. Although we can use existing spacecraft technologies to make ETT vehicles, it is a key issue to be studied further.

\section{Detecting leaks and finding leak posi- tions efficiently}

Gas leak will damage the vacuum environment in an ETT tube and increase the cost for maintaining the vacuum. There are three resources that lead to gas leak: (1) crack on tube wall; (2) seal bug at linkage positions such as emergency exits, pump outlets, and joint points between tube sections; and, (3) airlocks at stations.

For this ultra-large-scale vacuum chamber, daily measuring and leak detection is very important and challenging. However, helium mass spectrometer leak detection is not applicable. Some feasible methods to detect leaks and find leak positions efficiently are suggested as follows:

(1) Isolation gates must be set along the vacuum tube line, one isolation gate every $5-10 \mathrm{~km}$. Smaller distances between two adjacent isolation gates, for example, one every $2 \mathrm{~km}$, will assist to detect gas leak, but increase construction cost and Maglev running hazards. After operation ends, one should close all isolation gates and check all segments of the whole line, including detection of gas leak in each section.

(2) After closing isolation gates, by observing the vacuum gauge, one can find which segment is leaking. For that section, one would install vacuum gauges more densely, for example, one vacuum gauge every 20$100 \mathrm{~m}$. By observing all vacuum gauges in one section, one may be able to position where exactly the gas is leaking.

(3) Ultrasonic detection is also applicable for an ETT tube.

\section{Conclusions and suggestions}

According to the above analysis, some basic conclusions and suggestions can be made as follows:

(1) Pure steel tube and steel-concrete composite structure tube are applicable for ETT tubes.

(2) It is necessary to install vacuum pumps every 1 or $2 \mathrm{~km}$ and set airproof isolation gates every $5-10 \mathrm{~km}$ along the ETT line.

(3) It should be considered synthetically how to release heat in the ETT tube and how to avoid a large amount of solar radiation.

(4) Do not keep the wires in the ETT tube in uninsulated as possible. For some wires or electrodes that have to be uninsulated, a safe space from other uninsulated wires or electrodes should be maintained.

(5) Gas leak of ETT tube should be detected by different tube sections isolated by isolation gates.

This paper deals with some key vacuum technology issues to be solved in ETT, and some solutions have been suggested. In fact, there are still many vacuum technology issues that need to be discussed and many optimizing solutions proposed. Vacuum technologies within ETT will be one of the most important application areas in future transport system.

\section{Acknowledgements}

The authors wish to acknowledge the support and motivation provided by National Natural Science Foundation of China (No.50678152) and Scientific Plan Fund of Shaanxi Province (No.2009K09-24).

\section{References}

[1] L. Zhou, Z.Y. Shen, Progress in high-speed train technology around the world, Journal of Modern Transportation, 2011, 19(1): 1-6.

[2] Shanghai, From international airport Pudong to Lujiazui. http://www.transrapid.de/, 2011-06-06 (in Chinese).

[3] Yamanashi Maglev Test Line, http://www.rtri.or.jp/, 2011-06-06.

[4] Daryl Oster, Space Travel on Earth, http://www.et3.com, 2011-06-06.

[5] Z.Y. Shen, On developing high-speed evacuated tube transportation in China, Journal of Southwest Jiaotong University, 2005, 40(2): 133-137 (in Chinese).

[6] X. Zhou; Y. P. Zhang, Y. F. Yao, Numerical simulation on the aerodynamic drag of high-speed train in evacuated tube, Science Technology and Engineering, 2008, 8(6): 1626-1628.

[7] Y.P. Zhang, S.S. Li, B.L. Liu. Composite structure tube with steel layer and concrete layer which is the same with evacuated tube transportation, China Patent: 201020540727.6, 2010-09-26 (in Chinese).

[8] Y.F. Yao, Y.P. Zhang, Z.Y. Yu, Analysis of cooling schemes of linear motor in evacuated tube transportation, Vacuum, 2007, 44(5): 66-68 (in Chinese).

[9] Y.P. Zhang, S.S. Li, T.Q. Ding, A maglev vacuum tube transportation system with a thin wall and driving device outside the tube, China patent: 201010192101.5, 201006-06 (in Chinese). 